Research Paper

\title{
Clinical Eificacy of Cervical Length and Volume for Prediction of Labor Onset in VBAC Candidates
}

\author{
Yun Sung Jo, Gui Se Ra Lee, Narinay Kim, Dong Gyu Jang, Sa Jin Kim, and Young Lee ${ }^{\bowtie}$ \\ Department of Obstetrics and Gynecology, College of Medicine, The Catholic University of Korea, Seoul, Korea.
}

$\triangle$ Corresponding author: Young Lee, M.D. PhD. Department of Obstetrics and Gynecology, Yeouido St. Mary's Hospital, Yeouido-dong-62, 150-761, Yeongdeungpo-gu, Seoul, the Republic of Korea. Tel: +82. 2-3779-1217 Fax: +82. 2-780-6107 E-mail: ly@catholic.ac.kr.

() Ivyspring International Publisher. This is an open-access article distributed under the terms of the Creative Commons License (http://creativecommons.org/ licenses/by-nc-nd/3.0/). Reproduction is permitted for personal, noncommercial use, provided that the article is in whole, unmodified, and properly cited.

Received: 2012.08.14; Accepted: 2012.10.15; Published: 2012.10.17

\begin{abstract}
Background: The purpose of this research is to discover whether measurement of cervical length and cervical volume at term is helpful in predicting the onset of labor in VBAC candidates.

Methods: Transvaginal sonographic evaluations of the cervixes of pregnant women who desired to undergo VBAC were performed between 36 - 40 weeks gestation. Clinical information such as labor onset time, gestational age at delivery and delivery mode was gathered from medical records.

Results: A total of 514 pregnant women participated in this study. Cervical length was significantly longer in the group that delivered 7 days or more after measurement than in the group that delivered within 7 days of measurement $(43 \pm 0.77 \mathrm{~cm}$ vs. $2.99 \pm 0.72 \mathrm{~cm}, p<0.00 \mathrm{I})$. Cervical volume was significantly larger in the group that delivered at and after 7 days than in the group that delivered within 7 days $\left(29.2 I \pm I I .62 \mathrm{~cm}^{3} \mathrm{vs} .34 .07 \pm 13.41 \mathrm{~cm}^{3}, p=0.014\right)$. The cervical length ROC curve was significantly more predictive than the cervical volume ROC curve (AUC: $0.7 \mathrm{II}$ vs $0.594, p=0.00 \mathrm{I}$ ). There were no significant differences between the combined cervical length/volume ROC curve and the cervical length ROC curve alone $(p=$ 0.565 ). The AUC of the cervical length ROC curve to predict postterm pregnancy was 0.729 .

Conclusion: Measuring cervical length is helpful in predicting the onset of spontaneous labor within 7 days and posterm delivery in VBAC candidates.
\end{abstract}

Key words: Cervical length, Cervical volume, VBAC, labor.

\section{Introduction}

Vaginal birth after cesarean (VBAC) has a 2.1 times higher risk of perinatal mortality and hypoxic brain damage than a planned cesarean section [1]. This is mostly related to uterine rupture. The VBAC uterine rupture rate is $0.2 \sim 9 \%$, and the rate is higher in induced labor than spontaneous labor [2-4]. Predictions of labor onset in VBAC candidates will assist doctors in their obstetrical plans, and as a result will lead to a reduction in unnecessary induced labor and reduced uterine rupture risk. This will also allow the mother and family members to receive more information and thereby diminish potential anxiety.
The purpose of this research is to discover whether measurement of cervical length and cervical volume at term is helpful in predicting the onset of labor in VBAC candidates.

\section{Material and Methods}

This is an observational cohort study. The study was conducted between March 2007 and July 2011 in singleton pregnant women who wanted to try VBAC at St. Mary's Hospital in The Catholic University, Seoul, Korea. This study was approved by the Institutional Review Board (SC11RISI0210). Transvaginal 
sonographic evaluations of women's cervixes were performed between 36 - 40 gestational weeks. Exclusion criteria included a history of cervical conization, patients who had a uterine malformation, patients with painful regular uterine contractions and premature rupture of the membrane. Sonographic examinations were performed with a $3-8 \mathrm{MHz} 3 \mathrm{D}$ vaginal transducer (ACCUVIX XQ-3D, Medison, Seoul, Korea). Pregnant women were examined in the dorsal lithotomy position with an empty bladder. Cervical length was measured from the external os to the internal os along the cervical canal. If the cervical canal was not arranged in a straight line, the cervical length was divided into two or more lengths, which were then added together. After measuring cervical length, the same transvaginal probe was used in 3D mode to measure cervical volume. The cervix was scanned in 3D mode and divided into 15 parallel sections. Each sectional plane was manually drawn using the roller ball cursor of the system. Once all contours were drawn, the volume of the cervix was calculated automatically. All sonographic examinations were performed by one operator. We gathered clinical information such as labor onset time, gestational age at delivery and delivery mode from medical records.

An unpaired t-test was used to compare the demographic characteristics and cervical parameters by delivery interval using SAS version 8 (SAS institute Inc, Cary, USA). All values are indicated as mean +/SD. Receiver operating characteristic (ROC) curves were calculated using the MedCalc program (MedCalc 11.0, MedCalc software, Mariakerke, Belgium). $p<0.05$ was used to determine statistical significance.

\section{Results}

A total of 514 pregnant women participated in this study. Seventy-two women delivered within 7 days of measurement, while 442 women delivered 7 days or more after measurement. Of the 72 in the early group, 65 underwent spontaneous labor and 7 underwent induced labor. As shown in Table 1, we ruled out the 7 participants who had an induced delivery within 7 days of measuring the cervical length and volume. We compared the two groups - the delivered within 7 days by spontaneous labor group (early group) and the delivered at and after 7 days group (late group). The cervical length of the early group was $2.43 \pm 0.77 \mathrm{~cm}$, while that for the late group was $2.99 \pm 0.72 \mathrm{~cm}$. The cervical length was significantly longer in the late group $(p<0.001)$. The cervical volumes were $29.21 \pm 11.62 \mathrm{~cm} 3$ and $34.07 \pm 13.41 \mathrm{~cm} 3$ for the two groups, respectively, and thus the cervical volume was also significantly larger in the the late group $(p=0-014)$. We calculated ROC curves for cervical length, cervical volume and both combined to predict spontaneous labor and delivery within 7 days (Figs. 1 and 2). The cervical length ROC curve was significantly more predictive than the cervical volume ROC curve (AUC: 0.711 vs 0.594 , Fig. $1, p=0.001$ ). There were no significant differences between the combined ROC curve and the length-only ROC curve (Fig. 2, $p=0.565$ ). The prediction values for spontaneous labor and delivery within 7 days after measuring cervical length are shown in Table 2 (sensitivity, specificity, positive predictive value and negative predictive value).

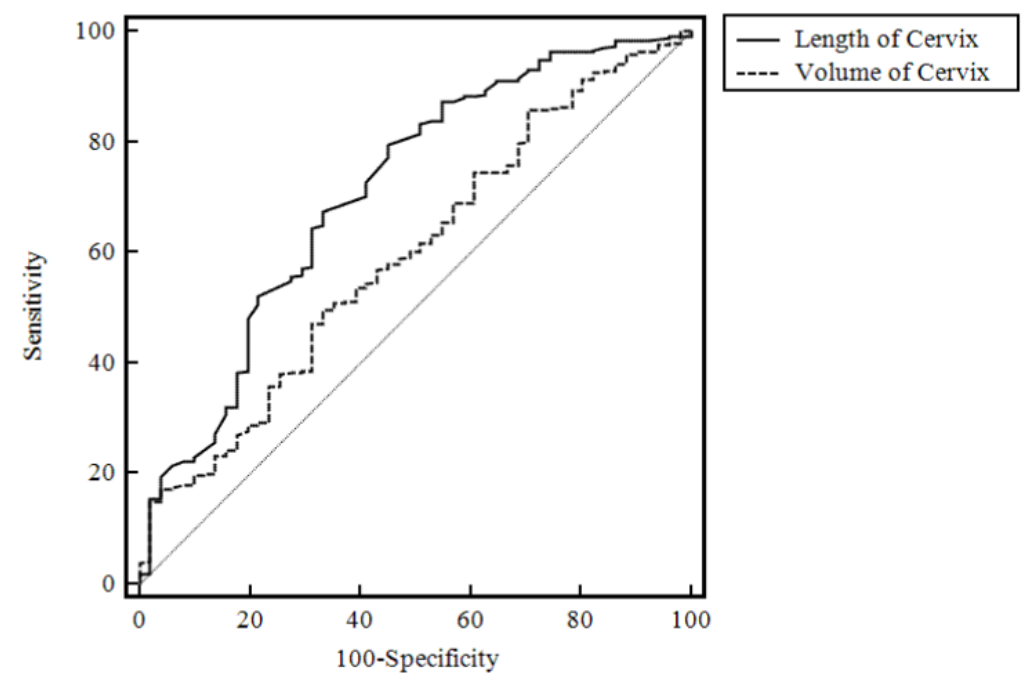

Figure I. ROC curve to predict the onset of spontaneous labor and delivery within 7 days after measurement. 


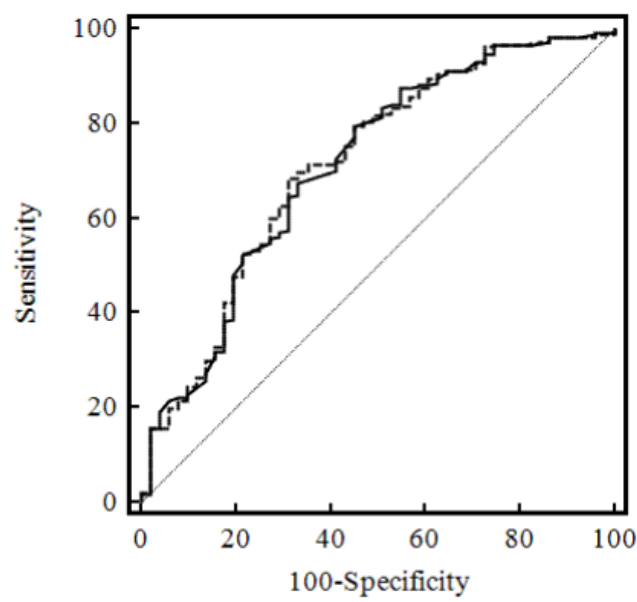

- Length of Cervix

---- Length and Volume of Cervix

Figure 2. Combined cervical length and volume ROC curve and length-only ROC curve to predict the onset of spontaneous labor and delivery within 7 days of measurement.

Table I. Cervical length and volume as a function of time from delivery/gestation

\begin{tabular}{|c|c|c|c|c|c|c|}
\hline & \multicolumn{3}{|l|}{ Interval days } & \multicolumn{3}{|c|}{ Gestational weeks at delivery } \\
\hline & $\begin{array}{l}<7 \text { days } \\
\text { from delivery }\end{array}$ & $\begin{array}{l}\geq 7 \text { days } \\
\text { from delivery }\end{array}$ & $p$-value & $<42$ weeks gestation & $\geq 42$ weeks gestation & $p$-value \\
\hline $\mathrm{N}$ & 65 & 442 & & 388 & 10 & \\
\hline $\begin{array}{l}\text { Cervical } \\
\text { length }(\mathrm{cm})\end{array}$ & $2.43 \pm 0.77$ & $2.99 \pm 0.72$ & $<0.001$ & $2.84 \pm 0.76$ & $3.41 \pm 0.58$ & 0.02 \\
\hline $\begin{array}{l}\text { Cervical vol- } \\
\text { ume }\left(\mathrm{cm}^{3}\right)\end{array}$ & $29.21 \pm 11.62$ & $34.07 \pm 13.41$ & 0.014 & $33.42 \pm 13.71$ & $33.13 \pm 8.67$ & 0.954 \\
\hline
\end{tabular}

In total, 504 women delivered before 42 gestational weeks, while 10 delivered after. Of the 504 women, 388 underwent spontaneous labor and 116 underwent induced labor. As shown in Table 1, we ruled out the 116 participants who had an induced delivery before 42 gestational weeks. We compared the two groups - the delivered group at or after 42 gestational weeks (postterm group) and the delivered group of before 42 gestational weeks (term group). The cervical length of the postterm group was significantly longer than the term group $(2.84 \pm 0.76$ vs. $3.41 \pm 0.58 \mathrm{~cm}, p=0.02)$. The cervical volume of the term group was $33.42 \pm 13.71 \mathrm{~cm}^{3}$, while that for the postterm group was $33.13 \pm 8.67 \mathrm{~cm}^{3}$, a difference that was not statistically significant $(p=0.954)$. Figure 3 shows the cervical length ROC curve for prediction of postterm pregnancy (greater than or equal to 42 gestational weeks). The AUC was 0.729. The prediction values for postterm pregnancy are shown in Table 3 (sensitivity, specificity, positive predictive value and negative predictive value).
Table 2. Cervical length prediction value of spontaneous labor and delivery within 7 days after measurement

\begin{tabular}{lllll}
\hline $\begin{array}{l}\text { Cervical } \\
\text { length }(\mathrm{mm})\end{array}$ & Sensitivity(\%) & Specificity(\%) & $\begin{array}{l}\text { PPV } \\
(\%)\end{array}$ & $\begin{array}{l}\text { NPV } \\
(\%)\end{array}$ \\
\hline 15 & 97.7 & 15.38 & 88.7 & 50 \\
20 & 91.8 & 30.8 & 90 & 35.7 \\
25 & 77.1 & 55.4 & 92.1 & 26.3 \\
27 & 67.8 & 66.2 & 92.9 & 22.2 \\
30 & 46.9 & 81.5 & 94.5 & 18.5 \\
\hline
\end{tabular}

Table 3. Cervical length prediction value of postterm delivery

\begin{tabular}{lllll}
\hline $\begin{array}{l}\text { Cervical length } \\
(\mathrm{mm})\end{array}$ & \multicolumn{3}{l}{ Sensitivity(\%) Specificity(\%) $\begin{array}{l}\text { PPV } \\
(\%)\end{array}$} & $\begin{array}{l}\text { NPV } \\
(\%)\end{array}$ \\
\hline 25 & 90 & 31.7 & 3.3 & 99.2 \\
27 & 90 & 42.8 & 3.9 & 99.4 \\
28 & 90 & 49.5 & 4.4 & 99.5 \\
30 & 70 & 60.1 & 4.3 & 98.7 \\
\hline
\end{tabular}




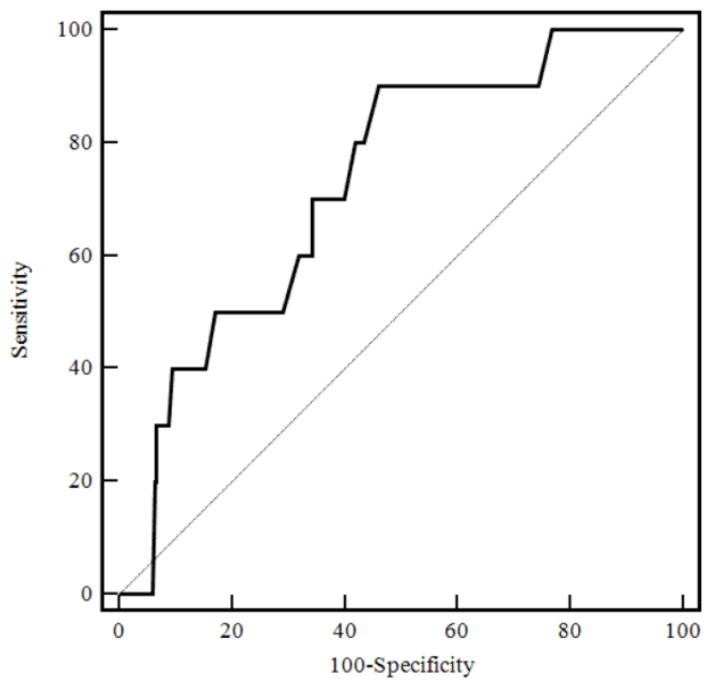

Figure 3. Cervical length ROC curve to predict postterm pregnancy.

\section{Discussion}

Approximately $73.6-75.5 \%$ of women who opt for VBAC will have a vaginal delivery $[5,6]$. If successful, VBAC has been shown to be associated with a lower incidence of maternal febrile mortality, need for blood transfusion and hysterectomy. However, those with failed VBAC have a higher risk of scar rupture, blood transfusion, infection and neonatal mortality and morbidity than those who undergo a planned cesarean section [7]. Spontaneous labor is associated with high success rates (80-74\%), while induced labor is associated with low success rates $(67 \%)$ [6]. The risk of rupture is nearly 3 times higher in women who undergo induced labor [8]. Because of this, the choice of induced VBAC labor causes a heavy psychological burden on pregnant women and their doctors. When obstetrics problems arise, accurate predictions of the onset of spontaneous labor may enable the clinician to provide precise information to the mothers and reduce the need for intervention.

Our research revealed that both cervical length and cervical volume are helpful in predicting the onset of spontaneous labor and delivery within 7 days in VBAC candidates, but cervical length is more useful than cervical volume (Figure 1). Furthermore, the combination of cervical length and volume shows similar prediction rates as those of cervical length alone (Figure 2). Therefore, to predict the onset of spontaneous labor and delivery within 7 days, only cervical length needs to be measured. Labor induction for postterm pregnancy is needed because perinatal mortality, including the risk of intrauterine fetal death, increases as pregnancy continues [9-11]. Thus, if prediction of postterm pregnancy is feasible and accurate, it may be possible to select high risk VBAC candidates for labor induction. High risk VBAC candidates can then change their delivery method to an elective cesarean section. Our results show that cervical length is useful in predicting postterm pregnancy, whereas cervical volume is not. Therefore, by measuring the cervical length in near term pregnant women, we can provide useful information to guide VBAC candidates and their families in their choice of delivery method.

Previous studies regarding the detection of labor onset by ultrasonography or by cervical length only did exclude women that had a previous history of cesarean section [12-15]. With the popularity of 3D ultrasounds, it is possible to more easily and precisely measure cervical volume $[16,17]$. Much research is being published on cervical volume using $3 \mathrm{D}$ imaging [18-20], but only one study has reported the value of cervical volume for predicting the onset of spontaneous labor at full term [14]. However, this study's focus was on postterm pregnant women $(\geq 41+5$ gestational weeks) and the number of participants was quite small $(n=60)$. We measured the cervical length and volume and compared the efficacy for prediction of spontaneous labor at full term in VBAC candidates. We found no additional benefits of measuring cervical volume in addition to length.

Currently, many studies regarding VBAC safety are being conducted. Labor induction elevates the risk of VBAC. Measuring cervical length at term is useful in predicting the onset of spontaneous labor within 7 days and postterm pregnancy in VBAC candidates. Predicting the onset of spontaneous labor and postterm pregnancy in VBAC candidates is an assessment of risk. The present study was the first attempt to stratify risk in women by measuring cervical parameters in VBAC candidates. A limitation of our study is that setting precise cut-off values for use in clinical settings is quite difficult (Tables 2 and 3). We expect that cervical length data could be used as part of a risk stratification system coupled with other clinical factors and we plan to develop such a system in future research.

\section{Competing Interests}

The authors have declared that no competing interest exists.

\section{References}

1. Rosen MG, Dickinson JC, Westhoff CL. Vaginal birth after cesarean: a meta-analysis of morbidity and mortality. Obstet Gynecol. 1991; 77: $465-470$.

2. Scott JR. Avoiding labor problems during vaginal birth after cesarean delivery. Clin Obstet Gynecol. 1997; 40: 533-541. 
3. Pridjian G. Labor after prior cesarean section. Clin Obstet Gynecol. 1992; 35: 445-456.

4. Martin JA, Hamilton BE, Ventura SJ, et al. Births: final data for 2001. Natl Vital Stat Rep. 2002; 51: 1-102.

5. Macones GA, Peipert J, Nelson DB, et al. Maternal complications with vaginal birth after cesarean delivery: a multicenter study. Am J Obstet Gynecol. 2005; 193: 1656-1662.

6. Landon MB, Leindecker S, Spong CY, et al. The MFMU Cesarean Registry: factors affecting the success of trial of labor after previous cesarean delivery. Am J Obstet Gynecol. 2005; 193: 1016-1023.

7. McMahon MJ, Luther ER, Bowes WA Jr, et al. Comparison of a trial of labor with an elective second cesarean section. N Engl J Med. 1996; 335: 689-695.

8. Landon MB, Hauth JC, Leveno $\mathrm{KJ}$, et al. Maternal and perinatal outcomes associated with a trial of labor after prior cesarean delivery. $\mathrm{N}$ Engl J Med. 2004; 351: 2581-2589.

9. Rand L, Robinson JN, Economy KE, et al. Post-term induction of labor revisited. Obstet Gynecol. 2000; 96: 779-783.

10. Hilder L, Costeloe K, Thilaganathan B. Prolonged pregnancy: evaluating gestation-specific risks of fetal and infant mortality. $\mathrm{Br} \mathrm{J}$ Obstet Gynaecol. 1998; 105: 169-173.

11. Cotzias CS, Paterson-Brown S, Fisk NM. Prospective risk of unexplained stillbirth in singleton pregnancies at term: population based analysis. BMJ. 1999; 319: 287-288.

12. Tolaymat LL, Gonzalez-Quintero VH, Sanchez-Ramos L, et al. Cervical length and the risk of spontaneous labor at term. J Perinatol. 2007; 27: 749-753.

13. Strobel E, Sladkevicius P, Rovas L, et al. Bishop score and ultrasound assessment of the cervix for prediction of time to onset of labor and time to delivery in prolonged pregnancy. Ultrasound Obstet Gynecol. 2006; 28: 298-305.

14. Rovas L, Sladkevicius P, Strobel E, et al. Three-dimensional ultrasound assessment of the cervix for predicting time to spontaneous onset of labor and time to delivery in prolonged pregnancy. Ultrasound Obstet Gynecol. 2006; 28: 306-311.

15. Miura H, Ogawa M, Hirano $H$, et al. Time-related changes of cervical length as a predictor of labor onset within one week using transvaginal ultrasonography. Acta Obstet Gynecol Scand. 2010; 89: 757-761.

16. Farrell $\mathrm{T}$, Leslie JR, Chien PF, et al. The reliability and validity of three dimensional ultrasound volumetric measurements using an in vitro balloon and in vivo uterine model. BJOG. 2001; 108: 573-582.

17. Chou CY, Hsu KF, Wang ST, et al. Accuracy of three-dimensional ultrasonography in volume estimation of cervical carcinoma. Gynecol Oncol. 1997; 66: 89-93.

18. Jo YS, Jang DG, Kim N, et al. Comparison of cervical parameters by three-dimensional ultrasound according to parity and previous delivery mode. Int J Med Sci. 2011; 8: 673-678.

19. Park IY, Kwon JY, Hong SC, et al. Usefulness of cervical volume by three-dimensional ultrasound in identifying the risk for preterm birth. Ultrasound Med Biol. 2011; 37: 1039-1045.

20. Hoesli IM, Surbek DV, Tercanli S, et al. Three dimensional volume measurement of the cervix during pregnancy compared to conventional 2D-sonography. Int J Gynaecol Obstet. 1999; 64: 115-119. 